\title{
CARACTERÍSTICAS NACIONAIS E ESTADUAIS DO CRESCIMENTO DA DEMANDA POR ETANOL HIDRATADO, GASOLINA C E AMBOS OS COMBUSTÍVEIS NO PERÍODO DE 2005 ATÉ 2013 NO BRASIL.
}

\author{
Sérgio Rangel Fernandes Figueira ${ }^{1}$
}

\section{RESUMO}

A utilização da gasolina como combustível automotivo é considerada como uma das principais fontes da emissão de gases causadores do efeito estufa. A utilização do etanol combustível produzido com cana-de-açúcar colabora para reduzir a emissão de gases geradores do efeito estufa, no entanto necessita da utilização de produtos químicos para sua produção como fertilizantes, fungicidas, herbicidas impactando na água e no solo. A pesquisa realizou uma análise quantitativa da situação da demanda pelo etanol hidratado, gasolina $\mathrm{C}$ e ambos os combustíveis nos Brasil e nas unidades federativas brasileiras entre 2005 (ano pelo qual a venda de veículos bicombustíveis se torna majoritária no Brasil) e 2013. Utilizou-se ainda a mensuração da Razão de Concentração para se avaliar a participação dos principais estados produtores de etanol na demanda nacional de etanol hidratado comparativamente com a participação destes estados na demanda por gasolina $C$ e ambos os combustíveis. A demanda nacional por ambos os combustíveis ampliou-se $84 \%$ no período analisado, passando de aproximadamente 28,22 bilhões de metros cúbicos em 2005 para 52,18 bilhões em 2013. A demanda por gasolina $C$ se eleva em aproximadamente $75,6 \%$, passando de 23,55 bilhões para 41,6 bilhões e a demanda por etanol hidratado se eleva em 134\%, passando de 4,6 bilhões para 10,8 bilhões. Constatou-se maior participação dos estados produtores de etanol na demanda por etanol hidratado em relação a demanda por gasolina $C$ e ambos os combustíveis. A participação dos estados produtores vem se reduzindo na demanda nacional de gasolina e ambos os combustíveis.

PALAVRAS-CHAVE: demanda nacional e estadual. Gasolina C. Etanol Hidratado.

\section{NATIONAL AND STATE CHARACTERISTICS OF THE GROWING DEMAND FOR HYDRATED ETHANOL, GASOLINE C AND BOTH FUELS FROM 2005 UNTIL 2013 IN BRAZIL.}

\footnotetext{
${ }^{1}$ Doutor, Professor Assistente Doutor na UNESP do Câmpus de Jaboticabal. figueira@fcav.unesp.br.
} 


\begin{abstract}
The use of gasoline as an automotive fuel is considered as a major source of greenhouse gas emissions. The use of ethanol fuel produced from sugarcane contributes to reduce the emission of gases causing the greenhouse effect, but requires the use of chemicals products for their production as fertilizers, fungicides, herbicides impacting on water and soil. The research conducted a quantitative analysis about the demand of hydrated ethanol, gasoline $C$ and both fuels in Brazil and in the Brazilian federal units from 2005 (the year in which the sale of flex fuel vehicles in Brazil becomes majority) until 2013. It was also measured the concentration ratio to evaluate the participation of the major producing states of ethanol in the domestic demand for hydrated ethanol compared with the participation of these states in the demand for gasoline $C$ and both fuels. The demand for both fuels has expanded $84 \%$ in the analyzed period, from approximately 28.22 billions cubic meters in 2005 to 52.18 in 2013 . The demand for gasoline $C$ increased approximately $75.6 \%$ in the period, from 23.55 billions cubic meters to 41.6 , and the demand for hydrated ethanol increased $134 \%$ in the period, from about 4.6 billions to 10.8. There was a higher participation of states producers of ethanol in the national demand for hydrated ethanol in comparison with the demand for gasoline $C$ and both fuels. The participation of producers states has been reduced in the domestic demand for gasoline $\mathrm{C}$ and both fuels.
\end{abstract}

\title{
LAS CARACTERÍSTICAS NACIONALES Y ESTATALES DE LA CRECIENTE DEMANDA DE ETANOL HIDRATADO, GASOLINA C Y AMBOS COMBUSTIBLES A PARTIR DE 2005 HASTA 2013 EN BRASIL.
}

\begin{abstract}
RESUMEN
El uso de la gasolina como combustible de automoción se considera como una de las principales fuentes de emisión de gases que causan el efecto invernadero. El uso de combustible de etanol producido a partir de caña de azúcar contribuye a reducir la emisión de gases que causan el efecto invernadero, pero requiere el uso de productos químicos para su producción como fertilizantes, fungicidas, herbicidas impactando sobre el agua y el suelo. La investigación llevó a cabo un análisis cuantitativo de la situación de la demanda de etanol hidratado, gasolina C y ambos combustibles en Brasil y los estados brasileños a partir de 2005 (año en que la venta de vehículos de combustible flexible se convierten en mayoría en Brasil) y 2013. También se utilizó el coeficiente de concentración para medir la participación de los principales estados productores de etanol en la demanda interna de etanol hidratado en comparación con la participación de estos Estados en la demanda de gasolina $\mathrm{C}$ y ambos combustibles. La demanda nacional de ambos combustibles se ha expandido $84 \%$ en el período analizado, a partir de 28,20 billón de metros cúbicos en 2005 hasta 52,18. La demanda de gasolina C aumenta alredor de $75,6 \%$, de 23,55 para 41,6. La demanda de etanol hidratado se incrementa en un $134 \%$, de 4,6 para 10,8. Hubo una mayor proporción de los estados productores de etanol en la demanda de etanol hidratado en relación con la demanda de gasolina $\mathrm{C}$ y ambos combustibles
\end{abstract}

PALABRAS-CLAVE Demanda nacional y estatal, Gasolina C, Etanol hidratado. 


\section{INTRODUÇÃO}

O aquecimento global passa a ganhar destaque como um problema para o meio ambiente a partir da década de 1980. O uso de combustíveis derivados do petróleo, como a gasolina, passou a ser percebido com um dos principais causadores da emissão de gases geradores do efeito estufa.

Pesquisa de Macedo (1997) diagnosticou que o uso do etanol produzido no Brasil provoca emissão de gases do efeito estufa $80 \%$ menor que o uso da gasolina. Utilizando-se de pesquisas como está, tanto o setor sucroalcooleiro brasileiro como o setor público passaram a adotar medidas para estimular a utilização do etanol combustível tanto no mercado interno como externo, através de concessão de financiamento público via Banco Nacional de Desenvolvimento Econômico e Social (BNDES) e alguns estados, como São Paulo, passaram a uma incidência de ICMS menor para o etanol hidratado em relação ao cobrado pela gasolina.

$\mathrm{Na}$ década de 2000, com o crescimento do uso de biocombustíveis em geral e do etanol combustível em particular no mundo e no Brasil, ocorreu um série de debates sobre os efeitos positivos e negativos do ponto de vista ambiental e social dos biocombustíveis em geral e do etanol em particular. O International Food Policy Reasearch (2014) tem destacado preocupação com o impactos dos biocombustíveis na mudança do uso da terra e Szmrecsányi et al. (2008) destaca entre outros aspectos o uso de fertilizantes e herbicidas impactando na água e no solo. Em defesa do etanol brasileiro, cita-se trabalho de Nogueira et al. (2008) que destacam que existem culturas como a citricultura que utilizam mais fertilizantes e herbicidas que a cana-de-açúcar. Nassar; Moreira (2013), salientam que o crescimento da produção canavieira no Brasil tem ocorrido em áreas já desmatadas e ocupadas com pecuária extensiva, minimizando o impacto do crescimento da cultura canavieira sobre as florestas brasileiras. Salienta ainda que existe uma quantidade significativa de terra ocupada com pecuária extensiva para ser explorado no Brasil.

A partir de 2009, as perspectivas para o etanol brasileiro no cenário internacional e nacional tornam-se negativas. A partir deste ano, vem ocorrendo 
decréscimo tanto das exportações internacionais como brasileiras de etanol combustível (Batista, 2014). No mercado interno, passa a ocorrer declínio da demanda por etanol hidratado, devido as crises de oferta causados por problemas climáticos e falta de investimento nos canaviais (Empresa de Pesquisa Energética, 2013) e a redução do preço real cobrado pela gasolina $C$ pela Petrobras desde 2008 como política do governo para evitar elevação da inflação (Colomer; Tavares, 2012).

Figueira $(2011,2013)$ ressaltam também que vem ocorrendo crescimento diferenciado na demanda por etanol hidratado nos diferentes estados brasileiros entre 2000 e 2011. Os estados produtores de etanol detêm uma participação significativa do mercado nacional em relação aos demais estados. Os menores custos para transporte do etanol e menor incidência de ICMS cobrado pelo etanol hidratado em relação à gasolina $\mathrm{C}$ são os responsáveis pela concentração de demanda de etanol hidratado nos estados produtores.

O objetivo geral do trabalho é o de analisar a evolução da demanda por etanol hidratado, gasolina e combustíveis automotivos entre 2005 e 2013 em âmbito nacional e nas unidades federativas brasileiras, período em que a venda de automóveis bicombustíveis se torna majoritária.

Para se cumprir o objetivo geral, os seguintes objetivos específicos serão analisados:

Mensurar a evolução quantitativa da venda de etanol, gasolina $C$ e ambos os combustíveis no mercado nacional.

Quantificar a evolução da venda de etanol, gasolina C e ambos os combustíveis nas unidades federativas brasileiras.

Analisar o índice de razão de concentração, para se mensurar a concentração da demanda nos mercados estaduais de etanol hidratado, gasolina c e ambos os combustíveis automotivos entre 2005 e 2013.

Justifica-se a realização desta pesquisa para se analisar como evoluiu a demanda por gasolina e etanol no período de 2005 e 2013. Pois a demanda principalmente por gasolina mas também por etanol hidratado tem impactos ambientais relacionados aos gases geradores do efeito estufa. Quanto ao etanol 
hidratado, a produção de cana-de-açúcar traz efeitos danosos ao meio ambiente como uso de fertilizantes e agrotóxicos impactando nos solos e na água.

Pretende-se ainda analisar o crescimento da demanda destes combustíveis em termos estaduais, existindo indícios que o mercado de etanol hidratado e gasolina $C$ está se expandindo de forma diferenciada nos estados brasileiros.

\section{DESENVOLVIMENTO}

O desenvolvimento do trabalho será subdividido em revisão de literatura, procedimentos metodológicos e resultados e discussões.

\subsection{REVISÃO DE LITERATURA}

A partir da década de 1980, as questões relativas ao aquecimento global começaram a ganhar destaque nas preocupações ambientais mundiais. Desde então, reforçam-se as evidências científicas sobre o agravamento do problema e seus impactos no meio ambiente, com alteração no regime de chuvas intensificando tempestades tropicais e furações. Desde a revolução industrial, o homem tem provocado crescimento de gases geradores do efeito estufa como Dióxido de Carbono $\left(\mathrm{CO}_{2}\right)$ e Metano $\left(\mathrm{CH}_{4}\right)$ através do uso intensivo de recursos fósseis carvão, petróleo e gás natural - e da destruição de florestas e ecossistemas (CARDOSO, [200-] )

Em junho de 1988, realizou-se em Toronto no Canadá a Conferência Mundial sobre Mudanças Atmosféricas, desde então organizou-se o Painel Intergovernamental sobre Mudança Climática, um grupo de trabalho encarregado de respaldar técnica e cientificamente as negociações desse tratado internacional, que deveria ainda ser negociado e definido. Em 1990, o IPCC publicou seu Primeiro Relatório de Avaliação, afirmando que a mudança climática representaria de fato uma ameaça à humanidade. Necessitando-se tomar providências para mitigar as emissões e se adaptar ao efeitos da mudança climática. O uso crescente de combustíveis automotivos principalmente 
derivados combustíveis fósseis como gasolina e óleo diesel são parte do problema no mundo (PEREIRA; MAY, 2003)

No Brasil, principalmente a partir do governo Juscelino Kubitschek vem ocorrendo estímulos públicos para se desenvolver o transporte rodoviário em detrimento do transporte ferroviário e se desenvolver no Brasil a indústria automobilística (GREMAUD; VASCONCELLOS; JÚNIOR, 2009). Desde a década de 1950, vem ocorrendo crescimento da produção de gasolina para uso automotivo no Brasil.

Na década de 1970, o Brasil desenvolveu o Programa Nacional do Álcool visando estimular a demanda e a produção por etanol como combustível automotivo em substituição ao uso da gasolina, produto derivado do petróleo. A motivação para se implantar este programa decorria da elevação do preço internacional do petróleo a partir de 1973, decorrente da política de cartel dos países exportadores de petróleo para elevar o seu preço. Como na época, o Brasil era um grande importador de petróleo, o governo brasileiro investiu e subsidiou a produção de etanol no país.

O uso do etanol como combustível vivenciou períodos de crescimento e crises desde então no Brasil. Entre a década de 1970 e meados da década de 1980 ocorreu grande crescimento da produção e do consumo de etanol tanto na forma de etanol hidratado, consumido puro, ou na forma de etanol anidro, misturado na gasolina. No final da década de 1980 e praticamente na década de 1990, a produção apresenta estagnação decorrente da crise fiscal do estado para se incentivar o uso do etanol e os menores preços do barril do petróleo no cenário internacional, desencadeando desestímulo para a utilização do etanol brasileiro. Após atravessar crise na década de 1990, a utilização do etanol hidratado volta a vivenciar crescimento na década de 2000 (FIGUEIRA, 2005).

Desde 2003, a indústria automobilística brasileira lança um mecanismo denominado "flex-fuel" ou bicombustíveis pelo qual os automóveis podem utilizar qualquer combinação de etanol hidratado e gasolina C. Ocorreu a partir deste ano um grande incremento na venda de veículos. Quando iniciou a venda de automóveis bicombustíveis em pequena escala no Brasil, aproximadamente $3,9 \%$ das vendas totais, a venda de veículos bicombustíveis elevou-se rapidamente atingindo $91,5 \%$ da 
porcentagem de novos automóveis comercializados no ano de 2009. Apenas em 2005 os veículos bicombustíveis começaram a ser comercializados majoritariamente no Brasil, atingindo participação de $52,7 \%$ na venda de novos veículos automotivos, diante de uma participação de 22,5\% em 2004 (TÁVORA, 2011).

Pesquisa realizada por Macedo (1997), diagnosticou que a utilização do etanol produzido a partir da cana-de-açúcar gera um crescimento menos intenso da emissão de gases do efeito estufa em relação a emissão destes gases pela gasolina. Representando em média emissões de gases do efeito estufa $80 \%$ menores do que as emissões da gasolina no uso como combustíveis automotivos.

Com a expectativa de crescimento das vendas de etanol tanto para o mercado externo como interno, o setor privado sucroalcooleiro brasileiro e o setor público passaram a adotar medidas para estimular a utilização do etanol combustível tanto no mercado interno como externo na primeira metade da década de 2000. Conforme Borges; Costa (2013) O governo brasileiro concedeu linha de financiamento do Banco Nacional de Desenvolvimento Econômico e Social (BNDES) para financiar a expansão canavieira e das usinas produtoras de etanol hidratado. Além disto, Costa; Guilhoto (2010) salientam que o governo paulista concedeu uma cobrança de ICMS menor para o consumo de etanol hidratado em relação à tributação da gasolina $\mathrm{C}$, $12 \%$ cobrado de ICMS sobre o etanol hidratado e $25 \%$ cobrado sobre a gasolina C.

A partir de 2009, vem ocorrendo decréscimo das vendas de etanol tanto para o mercado externo como interno. Quanto ao mercado externo, vem ocorrendo declínio das exportações brasileiras. As exportações globais devem cair em 2014 pelo terceiro ano consecutivo a níveis só vistos há oito anos, início do "boom" do biocombustível, e a produção global também mostra sinais de estagnação. Neste sentido, Brasil sozinho chegou a exportar o recorde de 5,124 bilhões de litros em 2008, mas os volumes nos anos seguintes seguiram erráticos.Em 2013, o país embarcou 2,9 bilhões de litros (Batista, 2014). No mercado interno, passa a ocorrer declínio da demanda por etanol hidratado, devido as crises de oferta causados por problemas climáticos e falta de investimento nos canaviais (Empresa de Pesquisa Energética, 2013) e a redução do preço real cobrado pela gasolina C pela Petrobras 
desde 2008 como política do governo para evitar elevação da inflação (Colomer; Tavares, 2012).

O crescimento da demanda por biocombustíveis em geral e etanol combustível em particular desencadeou intenso debate no meio acadêmico nacional e internacional relacionado aos aspectos ambientais positivos e negativos do uso dos biocombustíveis em geral e do etanol combustível em particular.

Devido ao crescimento do uso dos biocombustíveis em geral na década de 2000 e do etanol combustível em particular, instalou-se um debate no meio acadêmico internacional e nacional sobre os benefícios ambientais e os problemas desta fonte de energia.

No cenário internacional, pesquisas realizadas pelo International Food Policy Reasearch (2014), por exemplo, preocupa-se com a mudança do uso da terra gerado pela necessidade de incorporar uma maior quantidade de áreas agrícolas para a produção de culturas utilizadas para a produção de biocombustíveis. A mudança do uso da terra para biocombustíveis poderá desencadear perda de florestas nativas, desencadeando ampliação da emissão de gases do efeito estufa, e ampliar a pressão sobre a utilização da água.

No Brasil, trabalho de Szmrecsányi et al. (2008) alertam para o fato de o plantio da cana-de-açúcar e o processamento deste insumo para se transformar em açúcar e álcool provocam os seguintes danos ambientais: a utilização de agrotóxicos e fertilizantes impactam no solo e na água. Além disto, a forma de expansão da cultura sucroalcooleira, pela qual a produção canavieira deve estar próxima da usina devido a perecibilidade da cana-de-açúcar desencadeou perda de biodiversidade por não respeitar o código florestal e danos à paisagem, tornando-se uma monocultura na região. O trabalho também aponta que a cultura canavieira provocou elevação da concentração fundiária nos locais onde ocorreu elevação da produção canavieira.

Em defesa do etanol brasileiro, o Instituto de Comércio e Negociações Internacionais (ICONE) (2014) organiza uma série de pesquisas para refutar o impacto do etanol produzido no Brasil na mudança do uso da terra, defendendo que o crescimento da produção canavieira tem ocorrido em áreas ocupadas com pecuária extensiva e que o bioetanol não poderá ser produzido na região amazônica. Nogueira 
et al. (2008) defendem a produção canavieira brasileira alegando que a utilização de defensivos agrícolas defensivos agrícolas como Fungicida, Inseticida e Acaricida é menor se comparado a culturas como laranja, café, milho e soja. Utiliza menos herbicida que a citricultura, quantidades equivalentes a soja e mais herbicidas do que o café e o milho. Quanto ao consumo de fertilizantes por hectare, utiliza em média menos que o Algodão, o Café a Laranja e mais do que o Eucalipto, Feijão, Arroz, Trigo Milho e Soja.

Portanto, pode-se considerar que o uso de etanol como combustível emite menos gases do efeito estufa que a gasolina, mas possui inegavelmente impactos ambientais decorrentes principalmente da utilização de fertilizantes e herbicidas.

\subsection{PROCEDIMENTOS METODOLÓGICOS}

Os dados utilizados para se realizar a mensuração quantitativa de demanda por etanol hidratado, gasolina $\mathrm{C}$ e ambos os combustíveis no mercado nacional e estadual foram coletados junto ao "site" da Agência Nacional do Petróleo Brasileiro (ANP).

Inicialmente elaborou-se gráfico com a evolução quantitativa da demanda por gasolina $\mathrm{C}$, etanol hidratado e gasolina $\mathrm{C}$ no âmbito nacional e estadual.

Quanto ao índice de razão de concentração, foi mensurada a evolução da concentração para os quatro maiores estados produtores de etanol no Brasil: São Paulo, Paraná, Goiás e Minas Gerais, para se averiguar se existe maior concentração de demanda de etanol hidratado nestes estados em relação a gasolina $\mathrm{C}$ e a ambos os combustíveis. Salientando que estes estados também são importantes para a demanda por gasolina $\mathrm{C}$ e ambos os combustíveis devido a sua relevância em termos populacionais e econômicos para o país.

A fundamentação teórica do índice de Razão de Concentração foi elaborada a partir do trabalho de Hoffmann (1991). Este índice, tradicionalmente utilizado para se mensurar a concentração industrial, foi adaptado para mensurar a concentração da demanda estadual por etanol hidratado, gasolina C e combustíveis líquidos automotivos. 


\section{Volume 10, Número 5, 2014}

Direito Ambiental, Políticas Públicas e Sociedade

A razão de concentração permite analisar a participação dos principais estados na demanda total por etanol hidratado, gasolina C e combustíveis líquidos automotivos.

$$
y_{i}=\frac{X_{i}}{n \mu}
$$

Sendo Xi o valor do consumo do i-ésimo estado, $n$ o número de estados analisados e $\mu$ o valor médio da demanda por estado analisado.

Admitindo-se a seguinte ordenação da demanda:

$X_{1} \geq X_{2} \geq X_{3} \geq \ldots \geq X_{n}$

Então, a razão de concentração dos $k$ maiores estados demandantes é:

$$
C R_{k}=\sum_{i=1}^{k} y_{i}
$$

Sendo "i" o ordenamento do estado conforme sua participação na demanda e "yi" a participação na demanda.

\subsection{RESULTADOS E DISCUSSÕES}

Entre 2005 e 2009, a demanda por etanol hidratado no Brasil mais do que triplicou no período, passado de aproximadamente 4,6 bilhões de metros cúbicos em 2005 para 16,4 bilhões de litros em 2009, ver figura 1. Entre 2010 e 2012, ocorre uma queda na demanda por etanol hidratado, atingindo uma demanda de 9,8 bilhões de metros cúbicos em 2012 e um crescimento para 10,8 bilhões de metros cúbicos em 2013.

Figura 1: Evolução da demanda brasileira por etanol hidratado entre $2005 \mathrm{e}$ 2013.

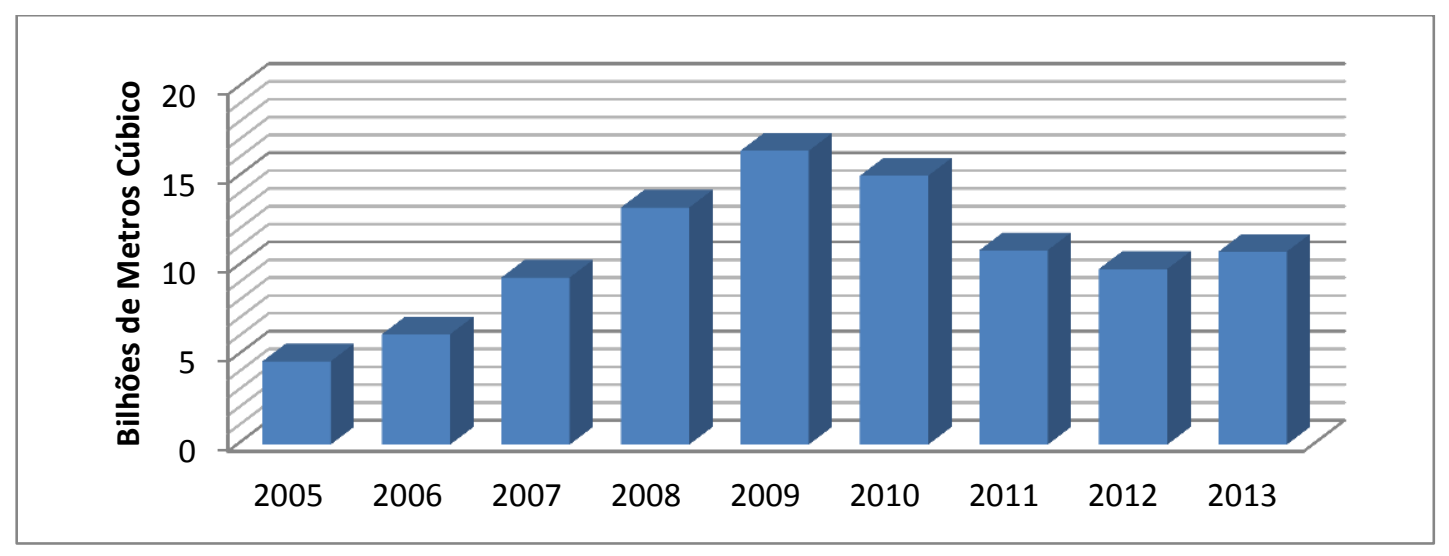

Fonte: Elaboração própria. 
Quanto a demanda por gasolina C, ocorreu expansão de aproximadamente 7\% entre 2005 e 2009, período de maior crescimento do etanol hidratado, passando de 23,55 bilhões de metros cúbicos em 2005 para 25,4 bilhões de metros cúbicos em 2009. A partir de 2010, a demanda por gasolina $C$ se amplia em aproximadamente $63 \%$ no mercado nacional passando de 23,55 bilhões em 2005 para 41, 6 bilhões de metros cúbicos bilhões de metros cúbicos em 2013, ver figura 2. Entre 2005 e 2013, a demanda por gasolina $\mathrm{C}$ se eleva em aproximadamente $75,6 \%$.

Figura 2: Evolução da demanda brasileira por gasolina C entre 2005 e 2013.

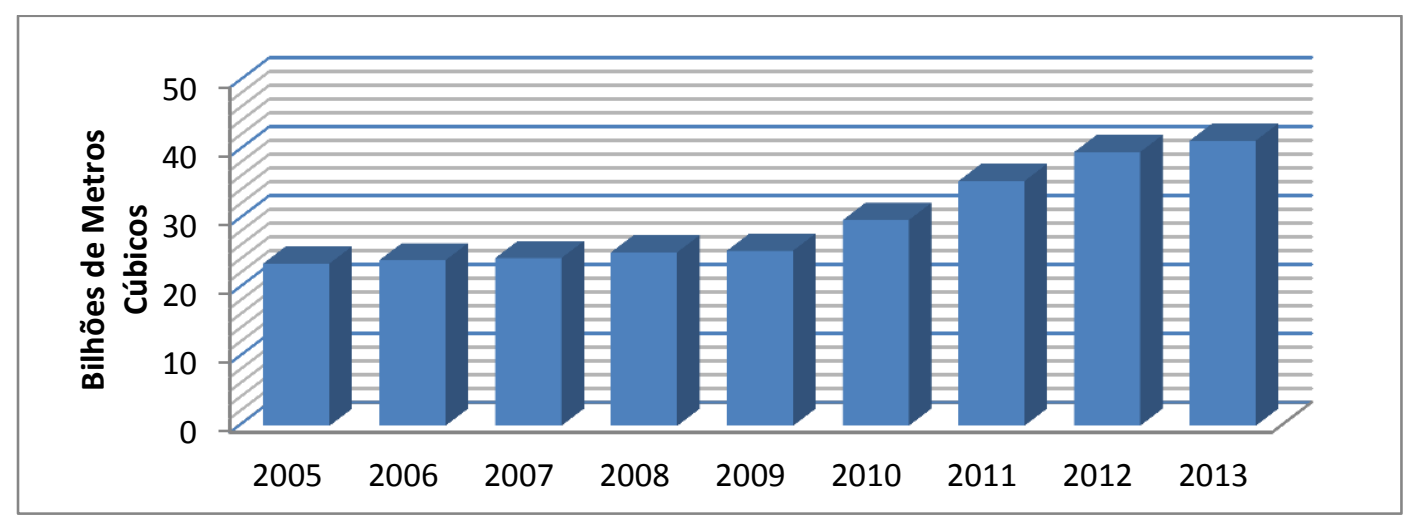

Fonte: Elaboração própria.

Quanto a demanda por ambos os combustíveis automotivos, soma do etanol hidratado e da gasolina C, ocorre elevação de aproximadamente $84 \%$ entre 2005 e 2013, passando de 28,22 bilhões de metros cúbicos em 2005 para 52,18 bilhões de metros cúbicos em 2013, ver figura 3 . 
Volume 10, Número 5, 2014

Direito Ambiental, Políticas Públicas e Sociedade

Figura 3: Evolução da demanda brasileira por gasolina $\mathrm{C}$ e etanol hidratado conjuntamente entre 2005 e 2013.

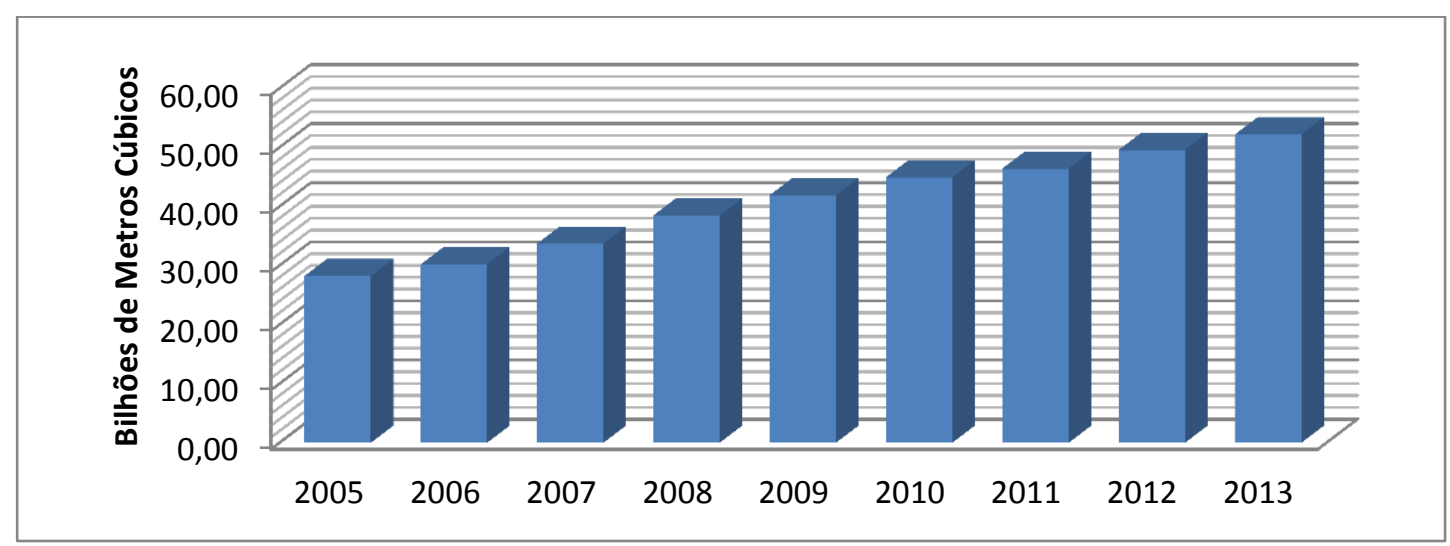

Fonte: Elaboração própria.

Considerando a evolução quantitativa demanda estadual por etanol hidratado entre 2005 e 2013, ver figura 4. Percebe-se como a demanda por etanol hidratado se mostra desigual entre os diferentes estados brasileiros. Os estados de São Paulo, Paraná, Goiás e Minas Gerais se mostram os maiores demandantes de etanol hidratado no país.

Figura 4: Evolução quantitativa da demanda estadual por etanol hidratado entre 2005 e 2013.

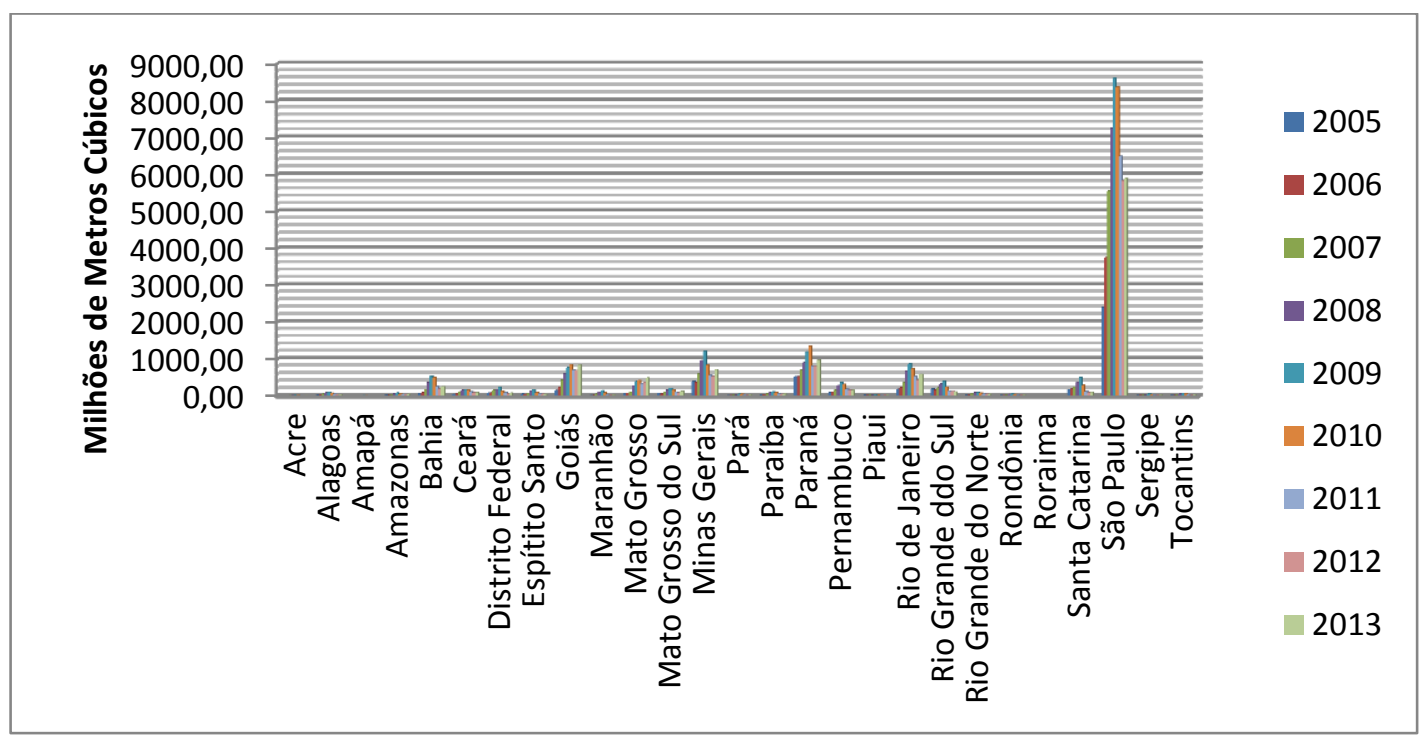

Fonte: Elaboração própria. 
Volume 10, Número 5, 2014

Direito Ambiental, Políticas Públicas e Sociedade

Como os estados de São Paulo, Paraná, Minas Gerais e Goiás também possuem participação significativa na população e no Produto Interno Bruto brasileiro, os estados também ocupam participação significativa na demanda por gasolina $\mathrm{C} \mathrm{e}$ ambos os combustíveis no país. Ao analisar a evolução quantitativa estadual da demanda por gasolina C entre 2005 e 2013, ver figura 5, nota-se crescimento mais acentuado da demanda por gasolina $\mathrm{C}$ em todos os estados brasileiros.

Figura 5: Evolução quantitativa da demanda estadual por gasolina $C$ entre 2005 e 2013.

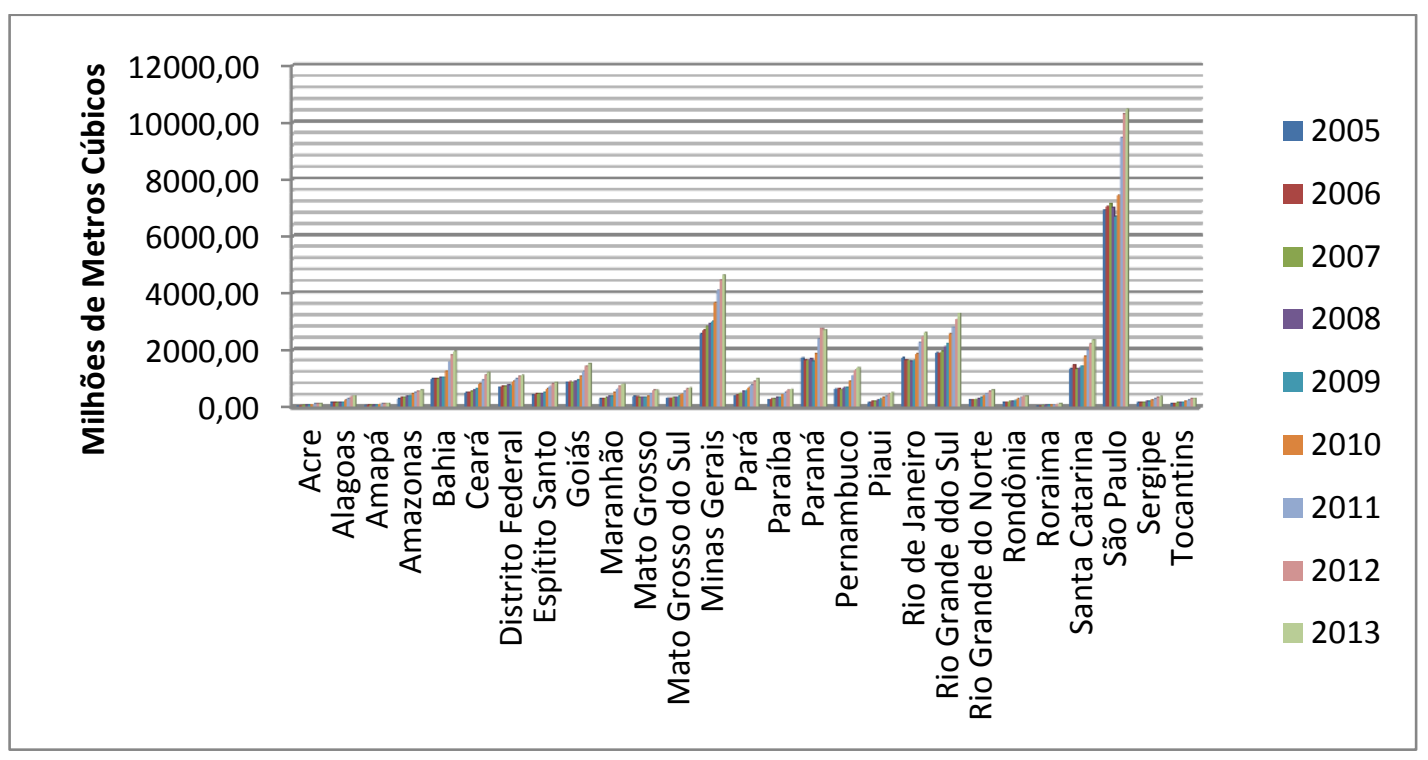

Fonte: elaboração própria.

Quanto a demanda por ambos os combustíveis, percebe-se crescimento em todos os estados brasileiros entre 2005 e 2013, ver figura 6. Nos estados da região Norte e Nordeste, a demanda por combustíveis mais que dobrou no período analisado. 
Figura 6: Evolução da demanda estadual por gasolina $C$ e etanol hidratado conjuntamente entre 2005 e 2013.

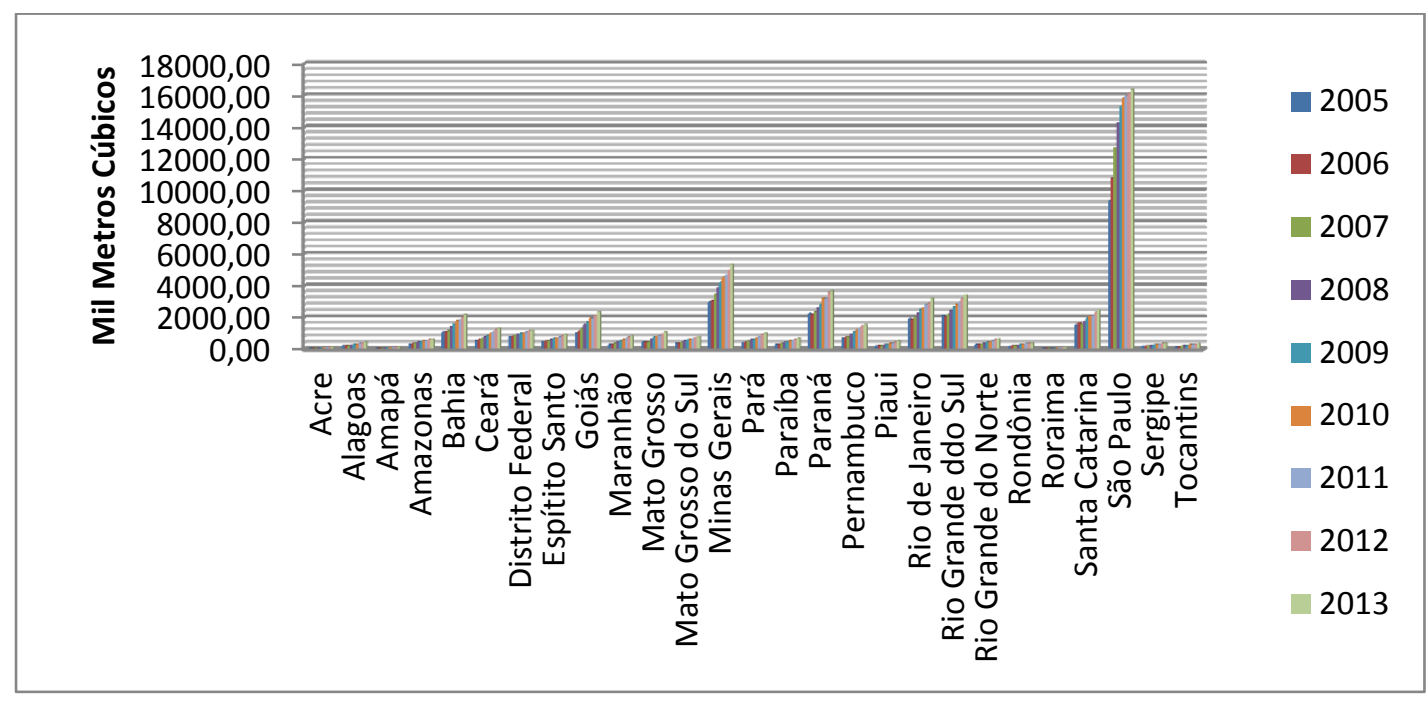

Fonte: Elaboração própria.

Para auxiliar na percepção sobre a concentração da demanda estadual de etanol hidratado, gasolina $\mathrm{C}$ e ambos os combustíveis. Utilizou-se da mensuração da razão de concentração para a demanda por etanol hidratado, gasolina $\mathrm{C}$ e ambos os combustíveis entre 2005 e 2013 nos estados de São Paulo, Minas Gerais, Paraná e Goiás, estados com maior participação na produção de etanol nacional.

A participação dos quatro estados com maior participação na produção de etanol brasileiro passou de aproximadamente 74,13\% em 2005 para aproximadamente $77,98 \%$ em 2013. No ano de 2012, estes estados adquiriram maior participação na demanda por etanol hidratado nacional, atingindo participação de aproximadamente $79,8 \%$, ver figura 7 . Percebendo-se uma significativa participação destes estados produtores de etanol na demanda por este tipo de combustível entre 2005 e 2013. 
Volume 10, Número 5, 2014

Direito Ambiental, Políticas Públicas e Sociedade

Figura 7: Participação dos estados de São Paulo, Minas Gerais, Paraná e Goiás na demanda nacional de etanol hidratado entre 2005 e 2013.

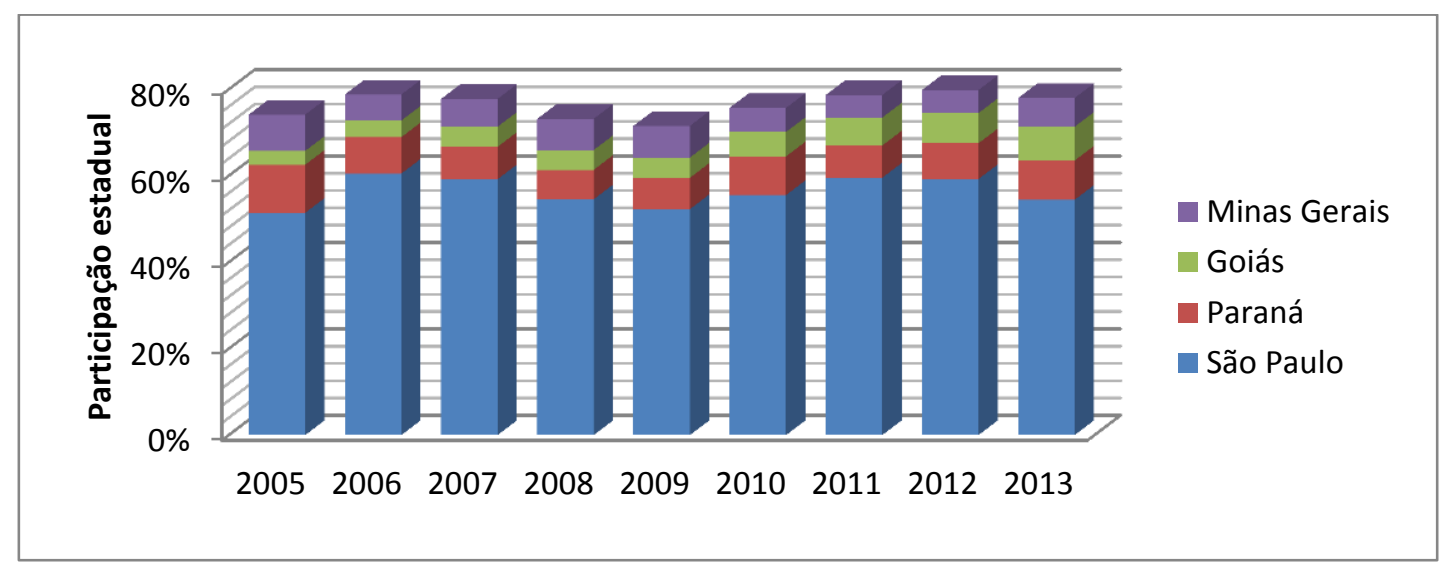

Fonte: Elaboração própria

Ao analisar a participação destes estados na demanda por gasolina C, a participação na demanda se reduziu de 51\% em 2005 para 47\% em 2013, ocorrendo declínio da participação dos estados produtores de etanol hidratado na demanda por gasolina C entre 2005 e 2013, ver figura 8.

Figura 8: Participação dos principais estados produtores na demanda por gasolina C entre 2005 e 2013.

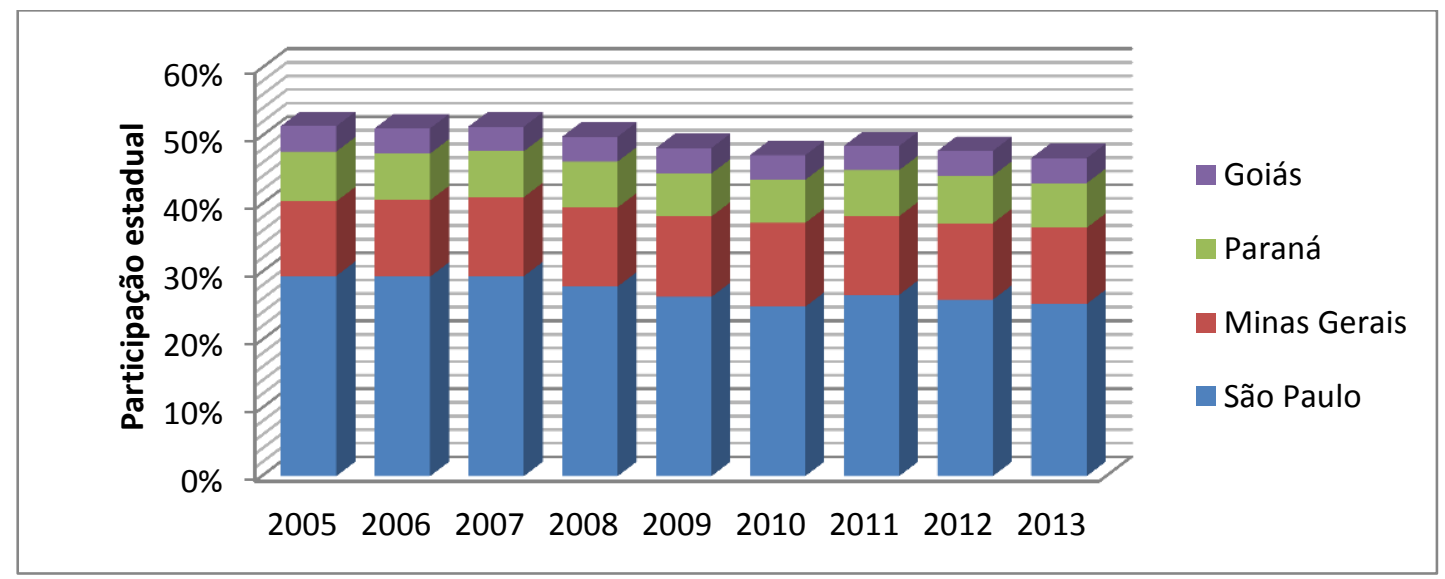

Fonte: Elaboração própria.

Ao se analisar a participação dos principais estados produtores na demanda por etanol hidratado e gasolina C entre 2005 e 2013, ver figura 9, percebe-se redução 
Volume 10, Número 5, 2014

Direito Ambiental, Políticas Públicas e Sociedade

na participação destes estados na demanda nacional de combustíveis. Entre 2005 e 2007, ocorre elevação da participação destes estados produtores na demanda por etanol hidratado e gasolina C de aproximadamente $55,21 \%$ para $58,72 \%$ entre 2005 e 2007. A partir de 2008 inicia-se declínio desta participação até atingir a participação de $53,24 \%$ em 2013.

Figura 9: Participação dos principais estados produtores na demanda por etanol hidratado e gasolina C entre 2005 e 2013.

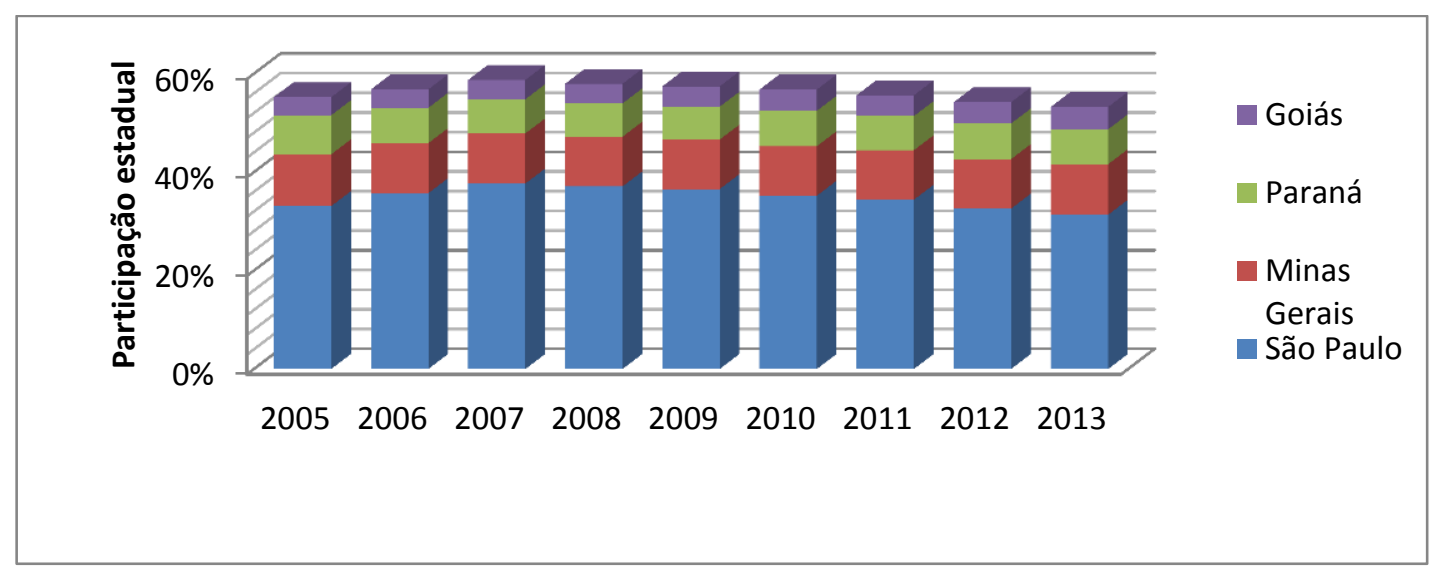

Fonte: elaboração própria.

Portanto, percebe-se nas unidades federativas brasileiras crescimento mais homogêneo no período analisado da demanda por gasolina $C$ e ambos os combustíveis. A demanda por etanol hidratado apresenta maior concentração nos estados produtores como decorrência do custo logístico e de diferença na incidência de tributação de ICMS entre etanol e gasolina $C$.

\section{CONCLUSÃO}

A utilização de produtos derivados do petróleo para a produção de combustíveis e geração de energia tem sido um dos grandes responsáveis pela emissão de gases do efeito estufa e provocado problemas ambientais. No final da década de 1990 e na década de 2000, os biocombustíveis em geral e o etanol em particular entraram no debate político e acadêmico sobre os seus benefícios e 
problemas ambientais e sociais. Se por um lado, constata-se uma menor emissão de gases de efeito estufa se comparado a gasolina, por outro amplia-se a poluição dos solos e da água gerados pelo uso de fertilizantes e agrotóxicos. Portanto, tanto a expansão do uso de gasolina C como de etanol possuem impactos ambientais. Quanto aos gases do efeito estufa, a gasolina possui maior impacto na emissão de gases, mas é importante ressaltar que o etanol hidratado também amplia a emissão de gases embora em menor nível. No entanto, a cultura canavieira e o processamento da cana-de-açúcar possuem impactos ambientais relacionados a utilização da água para a produção e poluição ambiental decorrente do uso de agrotóxicos e fertilizantes.

O presente trabalho analisou a evolução da demanda por etanol hidratado, gasolina C e ambos os combustíveis no nível nacional e estadual entre 2005 e 2013. Percebeu-se em nível nacional incremento de $84 \%$ na demanda por combustíveis automotivos entre 2005 e 2013. Quanto ao etanol hidratado, ocorreu crescimento de 4,6 bilhões de Metros Cúbicos para 16,4 bilhões em 2009. A partir deste ano, ocorre decrescimento da demanda, atingindo 10,8 bilhões de metros cúbicos em 2013. A demanda por gasolina se expandiu $76 \%$ no período, passando de 23,55 bilhões em 2005 para 41,6 bilhões de metros cúbicos em 2013. O crescimento mais vigoroso da demanda por este combustível se deu principalmente a partir de 2010.

Analisando o crescimento da demanda por etanol hidratado, gasolina $\mathrm{C}$ e ambos os combustíveis nas unidades federativas brasileiras, percebe-se que o crescimento da demanda por gasolina $C$ e ambos os combustíveis aconteceu em todas as unidades federativas brasileiras, com crescimento mais intenso nos estados do Norte e Nordeste. Os quatro maiores estados produtores de etanol: São Paulo, Minas Gerais, Paraná e Goiás possuem maior participação no mercado brasileiro de etanol hidratado do que de gasolina e ambos os combustíveis. Sugerindo uma concentração da demanda por etanol hidratado nestes estados, que além dos menores custos de transporte do etanol entre a produção e o consumo ainda contam com incidência de ICMS menor do etanol hidratado em relação à gasolina C. Quanto a gasolina $\mathrm{C}$, os estados não produtores de etanol hidratado apresentam crescimento mais intenso da demanda por gasolina $\mathrm{C}$ que os estados produtores. 
Sugere-se a realização de novas pesquisas para se analisar o impacto das variações dos preços da gasolina $\mathrm{C}$ e do etanol hidratado na demanda por estes combustíveis nos estados brasileiros e no Distrito Federal e analisar como o custo de logística e a incidência tributária diferenciada sobre os combustíveis no Brasil está influenciando em nível estadual na demanda por gasolina $\mathrm{C}$ e etanol hidratado.

\section{REFERÊNCIAS}

AGÊNCIA NACIONAL DO PETRÓLEO. Dados estatísticos mensais. Disponível em: < http://www.anp.gov.br/ ?id=548>. Acesso em: 15 fev. 2012.

BORGES, A.C.G.; COSTA, V.M.H.D. M. O processo de concentração e de centralização do capital e o financiamento da produção sucroalcooleira no Brasil. VII Simpósio Nacional de Geografia Agrária. João Pessoa, Paraíba. 2013.

BOÜET, A.; DIMARANAN, B.V.; VALIN, H. (2010) Modeling the global trade and environmental impacts of biofuel policies. Texto para Discussão para o International Food Policy Reasearch. Disponível em: http://www.ifpri.org. Acesso em 05/06/2014.

CARDOSO, P.H. et al. Mecanismo de desenvolvimento limpo. Rio de Janeiro: Conselho Empresarial Brasileiro para o Desenvolvimento Sustentável. [200-]. 87 p.

COlOMER, M.; TAVARES, A. Precificação de Combustíveis no Brasil e as Barreiras ao Investimento. Rio de Janeiro. Universidade Federal do Rio de Janeiro e Universidade Federal Fluminense. Texto para Discussão 4. 2012.

EMPRESA DE PESQUISA ENERGÉTICA. Análise de conjuntura dos biocombustíveis - ano 2013. Brasília. Ministério de Minas e Energia. 2013.64 p.

COSTA, C. C. ; GUILHOTO, J.J.M. Impacto da diferenciação do ICMS entre etanol hidratado e gasolina C para a economia do estado de Minas Gerais. In: VIII Encontro Nacional Enaber, 2010, Juiz de Fora. VIII Encontro Nacional Enaber, 2010.

FIGUEIRA, S.R. F. Reflexões sobre as características regionais e estaduais no mercado de etanol hidratado brasileiro entre 2000 e 2009. TUPÃ. SP. Periódico Eletrônico "Fórum Ambiental da Alta Paulista". 2011.

FIGUEIRA, S.R.F.; BORGES, A.C.G.; LOPES, D. Análise comparativa da evolução dos índices de concentração da demanda por etanol hidratado em relação. São Paulo: Revista Informações econômicas, 2013.

FIGUEIRA, S.R. Os programas de álcool como combustível nos EUA, no Japão e na União Européia e as possibilidades de exportação do Brasil. 2005. 182 p. Tese (Doutorado em Ciências, Área de Concentração: Economia Aplicada) - Escola Superior de Agricultura "Luiz de Queiroiz", Universidade de São Paulo, Piracicaba, 2005.

GREMAUD, A.P.; VASCONCELLOS, M.A.S.; TONETO, R. Economia brasileira contemporânea. 7ํed. São Paulo: Atlas, 2009. 
HOFFMANN, R. Estatística para economistas. São Paulo: Pioneira, 1998.

MACEDO, I.C. Greenhouse gas emissions and bio-ethanol production/utilization in Brazil. Piracicaba: Centro de Tecnologia Copersucar, 13 p , jan.1997.

MORAES, M.A.F.D. A Desregulamentação do Setor Sucroalcooleiro Brasileiro. 1999. 284 p. Tese (Doutorado em Ciências. Área de Concentração: Economia Aplicada) - Escola Superior de Agricultura "Luiz de Queiroz", Universidade de São Paulo, Piracicaba, 1999.

NASSAR, A.M.; MOREIRA, M. Evidences on Sugercane Expansion and Agricultural Land Use Changes in Brazil. 2013. Relatório para o Instituto de Estudos do Comércio e Negociações Internacionais (ICONE). Disponível em: http://www.iconebrasil.com.br/ publicacoes/ estudos/detalhes/569 Acesso em: 20/05/2014.

NOGUEIRA et al. Bioetanol de Cana-de-Açúcar - Energia para o Desenvolvimento Sustentável. Organização BNDES e CGEE. Rio de Janeiro: BNDES, 2008.

PEREIRA, A.S.; MAY, P.H. Economia do aquecimento global. In: MAY, P.H.; LUSTOSA, M.C.; VINHA, V. (Org.) Economia do Meio Ambiente. Rio de Janeiro: Elsevier ,2003.

SZMERCSÁNYI, T et al. Dimensões, riscos e desafios da atual expansão canavieira. Texto para Discussão para a Empresa Brasileira de Pesquisa Agropecuária (EMBRAPA). 2008. 